\title{
Racismo institucional: violação do direito à saúde e demanda ao Serviço Social
}

\author{
Helena Clécia Barbosa da Silva ${ }^{1}$ \\ https://orcid.org/0000-0003-1713-1237 \\ Telma Cristiane Sasso de Lima ${ }^{2}$ \\ https://orcid.org/0000-0002-7897-7722 \\ ${ }^{1}$ Universidade Federal de Alagoas, Faculdade de Serviço Social, Curso de Graduação em Serviço Social, AL, Brasil \\ ${ }^{2}$ Universidade Federal de Alagoas, Faculdade de Serviço Social, Curso de Graduação em Serviço Social, AL, Brasil
}

\section{Racismo institucional: violação do direito à saúde e demanda ao serviço social}

Resumo: O artigo aborda aspectos do racismo institucional como uma das expressões estruturais de violação do Direito à Saúde e da violência racial dirigida à população negra. Apoia-se na pesquisa realizada em 2019, em que fontes bibliográficodocumentais serviram para o mapeamento de acervos relacionados ao tema, publicados de 2010 a 2018 e os registros documentais obtidos em 2018 quando da observação do atendimento prestado por equipe de Serviço Social às mulheres em acompanhamento pré e pós-natal em uma maternidade pública. São analisadas as características das vulnerabilidades e das desigualdades que limitam o acesso da população negra aos serviços de saúde e configuram o racismo institucional, bem como as balizas legais e operacionais estruturadas, com base na PNSIPN, e incorporadas pelo Serviço Social para institucionalizar uma cultura antirracista também na formação e no exercício profissional.

Palavras-chaves: População Negra. Racismo na Saúde. Serviço Social.

\section{Institutional racism: right to health violation and demand to the social work}

Abstract: This paper addresses aspects of the institutional racism as one of the structural expressions of the Right to Health violation and the racial violence towards the black population. It is based on the research that was carried out in 2019, in which bibliographic and documental sources served to the mapping of collections related to the subject published from 2010 to 2018 and the documental records obtained in 2018 in the event of the observation of the care provided by a team of Social Workers to women undergoing prenatal and postnatal follow ups in a public maternity. There were analyzed characteristics of the vulnerabilities and inequalities that restrain the access of the black population to the health services and configure institutional racism, as well as the legal and operational reference points that are structured, according to "PNSIPN", and incorporated by the Social Work to institutionalize an anti-racist culture in both the academic and the professional settings. Keywords: Black Population. Racism in Health. Social Work.

Recebido em 06.10.2020. Aprovado em 15.12.2020. Revisado em 01.02.2021.

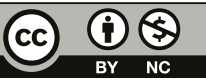

Este é um artigo publicado em acesso aberto (Open Access) sob a licença Creative Commons Attribution NonCommercial, que permite uso, distribuição e reprodução em qualquer meio, sem restrições desde que sem fins comerciais e que o trabalho original seja corretamente citado. 


\section{Introdução}

A discriminação racial institucionalizada e naturalizada no cotidiano da vida profissional de diferentes categorias revela, ainda hoje, a estrutura político, social e cultural que forjou a Nação brasileira sob contradições decorrentes da escravização da população negra. Constituímos uma sociedade falsamente tolerante e receptiva às diferenças, propagandeando respeito racial e cultural que reiteradamente é desmentido pelas estatísticas e diferentes exemplos de práticas racistas teimam em cercear, subjugar e depreciar as pessoas e suas expectativas de futuro pelo viés da diferença racial, pela cor.

Dados recentes apontam que 50,7\% da população brasileira são negras e vivem apartadas socialmente no espaço urbano, ocupando territórios periféricos, residindo em favelas sob condições insalubres e em situação de desemprego, ou subemprego e/ou precarizadas, ou ainda vítimas de trabalho escravo, possuem baixa escolaridade e estão mais suscetíveis a diversos tipos de violência que elevam os índices de morte por homicídios e de morbimortalidade por violações relacionadas à falta de acesso à prevenção e aos cuidados de saúde no Sistema Único de Saúde (SUS) (INSTITUTO DE PESQUISA ECONÔMICA APLICADA, 2019). Isso ilustra as maneiras pelas quais o racismo latente do/a brasileiro/a se expressa: violência estrutural e simbólica capilarizada em todos os aspectos da vida, reiterando à crença no mito de supremacia branca que transversaliza instituições, profissões e demarca estruturas de poder que responsabiliza os/as negros/as pelos fracassos socioeconômicos herdados historicamente.

Exploramos aqui os aspectos implicados no racismo institucional como expressão estrutural da violência racial dirigida às negras nos serviços de saúde pública. Os dados relatados resultaram da pesquisa realizada em 2019, em que fontes bibliográfico-documentais ${ }^{1}$ serviram para o mapeamento de acervos relacionados ao tema e os registros documentais do setor de Serviço Social no qual ocorreu a "observação participante" no atendimento prestado às mulheres em acompanhamento pré e pós-natal em uma maternidade pública. Durante o período de observação, acompanhamos inúmeras ações, dentre elas as rodas de conversas com foco no "Calendário Temático: Celebrações das Lutas das Mulheres" promovido pela Secretaria da Mulher e dos Direitos Humanos do Estado de Alagoas. No momento de: planejamento pela equipe de Serviço Social para seleção dos materiais didáticos; durante o diálogo com o grupo atendido; e após inúmeros depoimentos das usuárias percebemos que suas lutas estavam fortemente relacionadas às dificuldades de superação do preconceito racial. Ao destacarmos a variável raça/cor em cada uma das pautas de reivindicação/causas debatidas ou estudadas, constatamos a predominância de índices extremamente desfavoráveis à população negra.

Na pesquisa tivemos a motivação de reunir e demonstrar os aspectos implicados no quadro discriminatório vividos pelas usuárias nos serviços de saúde, tendo sido guiada pelos seguintes questionamentos: Quais as formas de expressão do racismo nas instituições/serviços de saúde? Existem diferenças na garantia do direito à saúde para a população negra? Como as profissões da saúde podem enfrentar cotidianamente o racismo institucional? Como o Serviço Social contribui para o acolhimento dos/as usuários/as que sofrem racismo e como pode assessorar na luta contra o racismo institucional?

Embora a legislação brasileira reconheça a saúde como direito universal sem distinção de raça/ cor, credo etc., no contexto observado, aparece como direito alienado porque, concretamente, o bem-estar físico e mental dos/as negros/as são limitados pelas dificuldades de acesso que esses indivíduos, seus grupos e famílias têm para acessar moradia, saneamento básico, educação, emprego, cultura, lazer, proteção etc. A violação de

1 Estudo de caráter exploratório-descritivo, de abordagem qualitativa cuja amostra das fontes bibliográficas foi definida pelo ano de publicação e em língua portuguesa, selecionada após buscas por publicações em bases online de Periódicos Eletrônicos. O levantamento ocorreu de maio a junho de 2019 através do uso dos seguintes descritores: "racismo", "racismo institucional", "Serviço Social", "saúde" e "saúde da população negra". Analisamos todas as publicações disponíveis no período de 2010 até 2018, basicamente artigos publicados em periódicos de Serviço Social e na Plataforma UNA-SUS. O ponto de corte para seleção das publicações foi de um (01) ano após a publicação da Portaria no 992/2009 que institucionalizou a PNSIPN. A amostra das fontes documentais observou os mesmos critérios e foi composta por 03 tipos de documentos: a) relatórios técnicos e publicações governamentais acessados nos sites oficiais do Ministério da Saúde, da Secretaria Estadual de Saúde de Alagoas e da Secretaria Municipal de Saúde de Maceió; b) publicações técnicas e normativas sobre o tema do Conselho Federal de Serviço Social; c) registros das observações de campo realizadas em 2018 durante o acompanhamento das ações profissionais de assistentes sociais em uma Maternidade pública na cidade de Maceió/AL (SILVA, 2019). 
qualquer um desses direitos impacta à saúde, agravando as variáveis associadas ao adoecimento e a adesão a tratamentos, especialmente daquelas doenças possíveis de ser evitadas ou controladas pela prevenção. Argumento reiterado pela pandemia COVID-19. Ao inscrevermos constitucionalmente a universalidade do direito que orienta a Política Nacional de Saúde brasileira, esperávamos que, se não automaticamente, em longo prazo houvesse mecanismos, formas e vontades que exigissem sua concretização, acolhendo, sobretudo a diversidade de gênero, de povos e de culturas.

Com a institucionalização da questão racial como diretriz no SUS, entre 2002-2004, houve certa priorização governamental na coordenação de esforços para mapear os dados de saúde da população negra e na reorganização de serviços e ações em todo o País. Em 2009, a aprovação da Portaria nº 992 instituiu a Política Nacional de Saúde Integral da População Negra (PNSIPN) para induzir ações comprometidas em superar as barreiras do racismo, apostando na equidade para dar condições concretas de acesso à população negra aos direitos constitucionais, reduzindo os danos históricos secundarizados pelo Estado. A partir daí, estabeleceramse novas diretrizes de trabalho para as equipes de saúde com foco no combate ao racismo nos três níveis de atenção do SUS, no sentido de coibir o uso de conceitos reforçadores de atitudes preconceituosas, ampliando a conscientização através de campanhas e de responsabilização legal quando violado o direito à diversidade.

As políticas e serviços públicos deveriam efetivar os Direitos, suprindo com equidade as lacunas existentes nos mecanismos de acesso. Nossas ações profissionais precisam seguir nessa visão de mundo, com premissa ética humanista dentro das instituições e como prática cidadã que não nega o passado, os erros e nem oculta o racismo. A partir das observações de campo, muitas vezes, as mulheres negras referiram não terem sido examinadas, muito menos ouvidas pelos/as profissionais de todas as categorias. Violações que acarretavam inúmeros problemas, especialmente traumas obstétricos, o medo e a desconfiança que percebiam nos/as profissionais brancos ao atendê-las (SILVA, 2019). Nas próximas duas seções expomos os dados levantados sobre as características das vulnerabilidades e das desigualdades que limitam o acesso da população negra aos serviços de saúde e configuram o racismo institucional, bem como as balizas legais e operacionais estruturadas com base na PNSIPN e incorporadas pelo Serviço Social para institucionalizar uma cultura antirracista na formação e no exercício profissional.

\section{População negra, direito à saúde e racismo}

Reunimos aqui os índices de violação ao Direito à Saúde da população negra que, historicamente, foi e é submetida a diferentes atrocidades cujas subjugações acarretaram-lhe diversos agravos em sua saúde física e mental. Desde o período escravagista brasileiro até a atualidade, é a parcela da população mais exposta às doenças contagiosas e às condições inabitáveis e insalubres, bem como vítimas de constante violência física e simbólica (preconceito religioso e cultural) (CRUZ, 1993).

De acordo com o IPEA, em 2008, a população negra representava 67\% do público total atendido pelo SUS, e a branca $47,2 \%$. A maior parte dos atendimentos concentra-se em usuários (as) com faixa de renda entre um quarto e meio salário mínimo, distribuições que evidenciam que a população de mais baixa renda e a população negra são, de fato, SUS-dependentes (BRASIL, 2017, p. 13).

Sobre o perfil das/os usuárias/os SUS verifica-se que, devido suas condições socioeconômicas, as/ os negras/os conformam a maioria em atendimento (BRASIL, 2017). Já as/os brancas/os, excetuando os pobres, normalmente tendem a pagar por serviços privados de saúde. Logo, as/os negras/os sofrem mais com a precarização dos serviços de saúde pública (por exemplo: longas filas, falta de médico, falta de material).

Os índices de mortalidade materna perfaziam, em 2012, 1.583 mortes; desse total 60\% eram de mulheres negras e $34 \%$ brancas. Outras variáveis sanitárias indicam o acometimento de doenças de maior incidência na população negra, tais como: a anemia falciforme, diabetes mellitus tipo II, hipertensão arterial, deficiência de glicose 6 e de fosfato desidrogenase. Comorbidades predominantes como causa de mortes por agravos na saúde dos/as negros/as. Associam-se a esses agravos de saúde, os índices de mortalidade por causas violentas, em 2012, com 71,5\% dos homicídios vitimaram negros. Conforme dados do Ministério da Saúde em levantamento de 2016: as/os negras/as têm número menor de consultas quando equiparado com a população branca: 74,8\% 
para pessoas brancas, $69,5 \%$ pretas e $67,8 \%$ pardas. Possuem menor escolaridade e mais filhos em idades precoces, passam por menos consultas de pré-natal etc. (BRASIL, 2017, p. 14-25, grifo nosso).

Para compreendermos de maneira qualificada as características do racismo institucional no SUS, necessitamos apreender o que é racismo:

[...] consiste na discriminação de pessoas, baseado em características fenotípicas, justificando a superioridade de uma raça sobre a outra. Sua construção derivou-se das teorias evolucionistas do século XIX, que influenciaram diversas áreas do conhecimento [...] defendiam a existência de raças diferentes, menosprezando os negros e valorizando os brancos europeus (SILVA; PALUDO, 2011, p. 7107).

O preconceito racial baseia-se no estereótipo: quanto mais o indivíduo possui as características físicas da raça negra, mais sofre discriminações devido ao preconceito racial de marca. O racismo desequilibra o acesso concreto às oportunidades em todos os campos sociais, dificultando o desenvolvimento cidadão/ã do/a negro/a. O racismo institucional é uma das variáveis discriminatórias de atitudes humanas que deveriam ser encaradas como:

fracasso coletivo de uma organização para prover um serviço apropriado e profissional para as pessoas por causa de sua cor, cultura ou origem étnica [...] detectado em processos, atitudes e comportamentos que totalizam em discriminação por preconceito involuntário, ignorância, negligência e estereótipo racista, que causam desvantagens a pessoas de minoria étnica. A prática do racismo institucional na área da saúde afeta preponderantemente as populações negra e indígena [...] (KALCKMANN et al., 2007, p. 146).

O tratamento diferenciado das pessoas negras são pré-julgamentos morais a partir de preconceitos estruturais. No caso da área da saúde e da atenção à saúde da mulher, os profissionais guiam-se, basicamente, em um único estereótipo associado ao senso comum cunhado por escravocratas: além de serem vistos como procriadoras e negligentes, consideram que as negras possuem maior capacidade de aguentar a dor (LOPES, 2005). A pesquisa de Figueiro e Ribeiro (2017, p. 92-93) destacou a fala de usuárias nessas condições: “[...]. Muitos falam [profissionais de saúde]: Ah... ela é negra, ela tem resistência! Ela aguenta! [enfático] [...] O negro não tem dor, que se vire que ele dê um jeito. Ele aguenta! [...]".

Não significa que o racismo institucional se restringe à área da saúde. Ele existe em diversas situações. Destacamos o funcionamento das polícias que, além do o uso excessivo da força, imputa desvantagens desde a origem sobre negros/as, submetendo-os/as a tratamentos diferenciados e a julgamentos morais a partir de desqualificações, tais como marginais, ladrões, vadios etc. e justiçamentos, como indicam Cerqueira e Moura (2013, p. 5), "o sistema de segurança pública age institucionalmente como capatazes protetores da elite branca".

Nas observações de campo, o uso de expressões pejorativas para definir as características de raça também ocorre com profissionais da saúde que as usam para justificar negligências nos exames necessários, sonegando tempo a explicações mais detalhadas sobre o quadro clínico, ao menosprezarem a capacidade cognitiva de negros/as. São outras expressões de racismo institucional: a) quando pacientes brancos/as se recusam a receber atendimento de um/a profissional negro/a; b) nos casos de estagnação na carreira profissional quando os/as negros/as não conseguem ascender a cargos mais bem remunerados devido sua cor; c) ou nos casos em que dentro da instituição existe diferença de tratamento entre os profissionais negros e brancos. A partir dos dados bibliográficos, destacamos que: d) a discriminação racial na saúde ocorre, muitas vezes, de maneira velada, reforçando estereótipos de senso comum (SILVA, 2019). Nem profissionais e nem usuários problematizam a falta de responsabilidade ético-política que perpetuam atitudes como:

Negligência no atendimento profissional; Não olhar, não tocar, não fornecer orientações; Oferecer menor número de consultas; Não seguir o protocolo de atendimento (a evidência científica) [ex.:] não modificar a medicação quando não atinge os resultados esperados; Utilização de expressões depreciativas (ou pretensamente carinhosas) em relação as/os usuárias/os negras/os; Atendimento diferenciado a usuárias/ os negras/os e brancas/os; Dificuldades em aceitar ser liderado/a por profissionais negros/as (CRUZ; MONTEIRO, 2016, p. 57). 
A incompreensão do racismo como crime, também não os deixa perceber o quanto ele afeta o percurso de cuidados dirigidos aos negros/as. Há inúmeros exemplos de resistência, por parte dos profissionais, em implementar as diretrizes de legislações e de políticas específicas. Isso se evidencia por meio de atitudes como:

Não coletar adequadamente o quesito cor (ou retirar do documento); Não analisar as informações; Não divulgar, não implementar a PNSIPN; Não incluir as questões étnico raciais e racismo nas ações de educação permanente em saúde; Falta de investimentos em ações e programas específicos de identificação de práticas discriminatórias; Resistência na adoção de mecanismos e estratégias de não discriminação, combate e prevenção do racismo, sexismo e intolerâncias; Falta de investimentos na formação de profissionais; Dificuldade em priorizar e implementar mecanismos e estratégias de redução das disparidades e promoção da equidade; Ausência do recorte étnico/racial na produção de informações; Ausência da população negra nos materiais promocionais; etc. (CRUZ; MONTEIRO, 2016, p. 57).

Assis (2018) acrescenta outro empecilho: o predomínio da lógica disciplinar e utilitarista nas instituições de ensino que dificulta/interdita revisões curriculares substantivas em prol de uma formação crítica e a absorver as "Diretrizes Curriculares Nacionais para a Educação das Relações Étnico-Raciais e para o Ensino de História e Cultura Afro-Brasileira e Africana” instituída pela Lei no 10.639/2003 (BRASIL, 2003, s/p). Conforme relatam Figueiro e Ribeiro (2017, p. 95) "na educação superior [...] essa resistência se agrava ainda mais com a constante negação do racismo".

Em relação à Saúde da Mulher, o racismo institucional afeta sobremaneira as negras no período gestacional, causando triplo sofrimento discriminatório: de classe, gênero e raça, conforme retrata a fala de usurárias durante o pré-natal ou mesmo no momento do parto:

[...] "Escutei a recepcionista (pré-natal) falar: negra é como coelho, só dá cria"; "No parto do meu último filho não me deram anestesia"; "O médico nem examinou a gestante negra". Ou ainda: "No pré-natal, só mandavam emagrecer eu nem sabia o que era eclampsia, quase morri” [...] (ASSIS, 2018, p. 549).

A discriminação de gênero é ainda mais pesada para a negra que sofre racismo, de acordo com Assis (2018, p. 549): existe uma grande ligação entre "violência obstétrica e racismo institucional", especialmente quando se observam que $92 \%$ dos óbitos maternos devido a ela poderiam ser evitados, pois decorrem de:

[...] hipertensão, hemorragia e infecção, [que] são as mais recorrentes. São entendidas como aquelas que ocorrem por complicações durante a gravidez, parto ou puerpério. Por conta de intervenções, omissões, tratamento incorreto ou um conjunto de fatores resultantes de qualquer dessas causas (ASSIS, 2018, p. 550).

O racismo também afeta a saúde mental da população negra em todas as fases da vida, quando ocorre na infância, os prejuízos são duradouros, levando as crianças a desvalorizar e/ou negar suas tradições e identidade ao perceberem negativamente sua cor, cultura etc., tendem ainda a preferir brinquedos e animais de cores brancas (PEREIRA; RISCADO, 2017). Os índices de suicídios em negros/as também estão associados ao racismo sofrido:

Enquanto a taxa de mortalidade por suicídio entre jovens e adolescentes brancos permaneceu estável de 2012 a 2016, o número aumentou $12 \%$ na população negra com a mesma idade. Analisando esses dois grupos em 2016, nota-se que a cada 10 suicídios em adolescentes e jovens aproximadamente seis ocorreram em negros e quatro em brancos (FIGUEIREDO, 2019, p. 1).

Portanto, atitudes racistas no Brasil não são fatos isolados/episódicos e compõem círculo vicioso que aparta pessoas, as desumanizando por destituí-las de seus direitos. Essa afirmação é ilustrada no perfil que construímos das usuárias acompanhadas na Maternidade: em sua maioria, mulheres de cor parda e negra chefes de família, com baixa escolaridade, moradoras de municípios interioranos de Alagoas ou da periferia de Maceió, possuíam mais de dois filhos, com pouca formação ocupacional e/ou estavam desempregadas. Ao mesmo tempo, em que elas entendiam que vivem sob situações de desigualdades e discriminação, não as relacionavam com fatores sociais estruturais que, através do racismo, limita o acesso aos seus direitos. Muitas delas repercutiram o pensamento hegemônico de responsabilização do/a negro/a pelas suas condições 
de saúde e, também, socioeconômicas. Houve relatos de usuárias/os impregnados de um caráter ideopolítico conservador que, sem perceberem, as violentava ainda mais (SILVA, 2019).

As atitudes cotidianas dos profissionais de saúde não materializam os programas nacionais dedicados a induzir e institucionalizar práticas democráticas e humanizadas no SUS, pois caso as equipes se comprometessem eticamente em executar as diretrizes legais existentes mudariam, substancialmente, as abordagens cotidianas com os/as usuários/as e, em longo prazo, protocolos dos serviços que poderiam gerar resultados diferentes ao combater o racismo que praticam (FIGUEIRO; RIBEIRO, 2017). Até mesmo a Organização das Nações Unidas (ONU) considera que no Brasil não existe democracia racial justamente pelas características mensuradas aqui. Na próxima seção expomos os dados que nos aproximam de respostas sobre: quais bases legais e quais tipos de ações profissionais existem ou são necessários construir para que possamos enfrentar concreta e cotidianamente o racismo institucional?

\section{Aportes ao enfrentamento do racismo institucional na Saúde e no Serviço Social}

Foi através da PNSIPN que parte das reivindicações do Movimento Negro foram institucionalmente absorvidas, no sentido de expor o racismo institucional e de reorganizar o SUS para o enfrentamento sistemático das discriminações. As ações iniciais para sua implementação envolveram: a) capacitação dos recursos humanos; b) indução da vontade política para encarar o racismo como crime, criando e efetivando mecanismos de controle e punição para os casos de recusa de atenção e de preservação dos direitos humanos nas instituições de saúde. Em cursos ofertados pela UNA-SUS, pretendia-se impactar a formação profissional de modo a estimular que:

[...] cada profissional de saúde examine suas próprias crenças quanto à população negra e sua cultura de matriz afro-brasileira. É a consciência crítica de suas crenças e, especialmente, de suas atitudes a condição que lhe assegura a prestação de um cuidado de saúde centrado na pessoa, no ser humano [...] correlacionando a influência da cultura, da família, da história, da resiliência e da genética da população negra brasileira com a saúde-doença e bem-estar (CRUZ; MONTEIRO, 2016a, p. 03).

O incentivo à capacitação dos profissionais da saúde para o acolhimento e a atenção à saúde da população negra tem foco no cumprimento das metas de: registro qualificado de dados; criação de novos projetos e estudos; proposição de protocolos de atendimento dentro das unidades de saúde; pactuação de responsabilidades na execução de ações nas três esferas de Governo e nos três níveis de atenção do SUS etc. Metas necessárias para fomentar políticas públicas eficazes no enfrentamento das vulnerabilidades vividas por grupos populacionais específicos (BRASIL, 2017, p. 8-9). Significa que a questão racial passou a ser compreendida factualmente como determinante social no processo saúde-doença.

As diretrizes da PNSIPN necessitam de uma rede estratégica que firme "Termos de Compromisso de Gestão" em torno das questões étnicos-raciais. A sua efetiva implementação depende, no âmbito federal, de ações que induzam sua execução sistemática em todo o território nacional através da gestão e da regulamentação da alocação de recursos financeiros para este fim, cabendo ao Ministério da Saúde coordenar e monitorar a implementação dessa política, pois integra o Plano Nacional de Saúde e o Plano Plurianual, responsabilizandose em estabelecer parcerias, monitorar sua implementação em todos os níveis de atenção do SUS. Aos Estados compete programar as ações e responsabilidades descentralizadamente, apoiando técnica e financeiramente os Municípios, bem como estruturando ações de capacitação dos recursos humanos em torno de particularidades regionais. Em âmbito municipal, a competência é de execução, nos territórios, da atenção direta a indivíduos, grupos, famílias e comunidades, estabelecendo prioridades e cronogramas para o alcance concreto das metas nos locais onde a população negra sofre mais com discriminação racial ou em vulnerabilidade de violência, como em comunidades quilombolas; pessoas no sistema prisional etc. (BRASIL, 2017).

No entanto, após dez anos da aprovação da PNSIPN, em 2019 apenas 57 municípios brasileiros a implementaram e a maioria dos profissionais de saúde sequer possuem sabe de sua existência, evidenciando o descaso dos governantes. Resta às instituições formadoras, como a UNA-SUS, seguir a oferta de cursos de especialização voltados para a divulgação da PNSIPN, apostando que a educação ético-profissional estimule sua institucionalização nos serviços. 
Além da demora na implementação da PNSIPN pelos Municípios, Cruz e Monteiro (2016b) informam que há lacunas na documentação de dados que dariam suporte científico ao trabalho técnico, pois para dispormos de dados fidedignos sobre a saúde da população negra precisamos de ações sistemáticas de registro do quesito cor no Sistema de Informação sobre Mortalidade (SIM), no Sistema de Informação sobre Nascidos Vivos (SINASC), no Sistema Nacional de Notificação de Agravos (SINAN).

Das ações de assistentes sociais esperam-se claras posturas críticas, técnica e eticamente comprometidas com a acolhida, a escuta e o encaminhamento qualificado. Atentar às contradições na implantação da PNSIPN é fundamental para construir projetos, pesquisas e ações de promoção e de amparo competente, isso significa para o Serviço Social:

[...] estar articulado e sintonizado ao movimento dos trabalhadores e de usuários que lutam pela real efetivação do SUS; conhecer as condições de vida e trabalho dos usuários, bem como os determinantes sociais que interferem no processo saúde-doença; facilitar o acesso de todo e qualquer usuário aos serviços de saúde da instituição e da rede de serviços e direitos sociais, [...] contida no projeto de Reforma Sanitária; buscar a necessária atuação em equipe, tendo em vista a interdisciplinaridade; estimular a intersetorialidade [...] articulação entre as políticas de seguridade social, [...]; tentar construir e/ou efetivar [...] espaços nas unidades que garantam a participação popular e dos trabalhadores de saúde nas decisões a serem tomadas; elaborar e participar de projetos de educação permanente; buscar assessoria técnica e sistematizar o trabalho desenvolvido [...]; assessorar os movimentos sociais e/ou os conselhos gestores [...] ampliando os canais de participação da população na formulação, fiscalização e gestão das políticas de saúde [...] (CONSELHO FEDERAL DE SERVIÇO SOCIAL, 2011, p. 30-31).

O Código de Ética Profissional de Assistentes Sociais de 1993 preconiza posturas antirracistas e orienta os/as assistentes sociais na construção de ações que favoreçam o combate ao racismo nos diversos espaços ocupacionais (CONSELHO FEDERAL DE SERVIÇO SOCIAL, 2011). No entanto, Eurico (2013) afirma que ainda são tímidas as abordagens da profissão. Isso se agrava com a pouca qualificação sobre o tema, empobrecendo as ações socioeducativas que deveriam pautar o racismo.

Não o consideramos responsabilidade exclusiva de assistentes sociais, pois no processo coletivo de trabalho todos os profissionais da saúde partilham a responsabilidade de acolhimento integral das necessidades do/a usuário/a negro/a. Do ponto de vista operacional, ao/à assistente social cabe realizar abordagens socioeducativas que debatam e organizem os recursos sociais aos quais os/as usuários/as têm direito, além de potencializar as redes de proteção social necessárias ao enfrentamento das discriminações étnico-raciais. Para tanto, o Conselho Federal de Serviço Social e os Conselhos Regionais de Serviço Social encaminharam uma campanha nacional (2017-2020) sob o lema "Assistentes Sociais no Combate ao Racismo", estimulando a produção de dados e reflexões sobre as demandas da população negra. Em 2019, a ABEPSS passou a executar o projeto "Subsídio ao Debate da Questão Étnico-Racial na Formação em Serviço Social” voltado para a incorporação das pautas raciais na formação de assistentes sociais de modo a efetivar a cultura antirracista. Trata-se da indução de ações que capacitem na apropriação de aspectos implicados na questão racial, tais como:

Combate a todas as expressões (práticas e ideológicas) que alimentem as teorias do embranquecimento e o mito da democracia racial; Garantia de que o racismo seja tratado como crime inafiançável; [...]; Salário igual para trabalho igual [...] Investimentos sociais para a comunidade negra (inclusive a quilombola); Cotas para os concursos e serviços públicos [...]; Fim de todas as formas de terceirização e precarização, que atingem particularmente [...] mulheres negras; Combate à violência racista e ao genocídio da juventude negra; Fim da perseguição e criminalizações dos movimentos e ativistas; Atenção médica às enfermidades com maior incidência entre negros/as [...]; Defesa da Ação Direta de Inconstitucionalidade (Adin 4887/03), para que os quilombolas tenham reconhecida a titulação de suas terras; Cotas e outras formas de ações afirmativas para acesso à educação [...], desvinculadas das cotas sociais; Garantir políticas de permanência e bolsas para os/as estudantes cotistas; Combate à discriminação religiosa [...] (CONSELHO FEDERAL DE SERVIÇO SOCIAL, 2017, p. 2).

Assis (2018) destaca que, no Brasil, a cidadania se efetiva sob diferenças sociais abissais que legalizam e legitimam as estruturas reprodutoras de desigualdades. Nesse contexto, as políticas sociais têm pouca capacidade de distribuição efetiva de renda. Apesar desse entrincheiramento numa cidadania desigual, os/as 
negros/as são historicamente insurgentes e inconformados e isso fica nítido no histórico repertório políticoorganizativo do Movimento Negro dedicado à desnaturalização do racismo, mantendo sua identidade cultural e arrancando seus direitos das mãos de brancos discriminadores.

\section{Considerações finais}

A PNSIPN tem 10 anos e são poucas as produções acadêmicas e técnicas que a problematizam. As existentes reiteram que as atitudes dos profissionais de saúde seguem desrespeitando as particularidades que incidem na saúde da população negra. Somado ao fato de, em pleno século XXI, o Brasil protagoniza retrocessos ao ter no Executivo Federal uma equipe de governo autoritária, fascista, racista, negacionista e neoliberal. Há muito que as políticas de saúde, previdência e assistência social estão secundarizadas, mas a situação piorou. Desde 2017, com a aprovação da PEC do Teto de Gastos (BRASIL, 2016) e com a vitória política do neoconservadorismo no pleito de 2018 , o contexto atual impacta ainda mais negros/as, sobretudo em meio à pandemia da COVID-19 que ceifou a vida de milhares de brasileiros/as, revelando uma política eugenista à brasileira incentivada pelos órgãos oficiais, resultando na proliferação descontrolada do vírus SARS-COV-2.

A situação que impôs o distanciamento e isolamento social escancarou as estruturais disparidades socioeconômicas. A população negra não conseguiu aderir e foi quem absorveu os impactos diretos da pandemia: aumento da precarização e/ou perda de emprego; maior risco de contaminação, adoecimento e incidência de óbitos; aumento da exposição à violência doméstica e da polícia nas comunidades onde residem precariamente; dificuldades para manter cuidados higiênicos básicos devido à falta de água, saneamento básico, transporte público adequado etc. Além disso, executam trabalhos informais sem capacidade de poupança ou de seguro social, isso os obriga a manter suas atividades laborais. Conforme veiculado em diferentes matérias jornalísticas, de março a setembro/2020, a crise só aumentou, estimulada pela desqualificação dos agentes de Estado que trataram com desdém: as graves consequências sofridas pela população; o trabalho dos profissionais de saúde; a gestão no Ministério da Saúde cuja equipe não tem formação epidemiológica e dificulta os recursos e os suportes que deveriam ser garantidos às equipes na linha de frente e aos usuários sem tratamento em leitos hospitalares adequados etc. Essas posturas culturais e institucionais vindas de quem deveria equilibrar o jogo (o Estado), quando um lado está em desvantagem histórica (população negra), termina interditando o diálogo e a superação do racismo. Reforça-se um tipo de conservadorismo que subverte em consumo o princípio de liberdade humana, relativizando-a como opções e preferências ao pressupor que todos/as os/as brasileiros/as usufruem de um mesmo patamar de oportunidades.

Esse caos sanitário e político atrasa ainda mais a implementação da PNSIPN, a execução de ações concretas de enfrentamento ao racismo nos serviços de saúde e a produção científica de dados sobre seus impactos reais na saúde da população negra. Esta pesquisa detectou que muitas das bibliografias levantadas continham problematizações rasas e tendenciosas, escamoteadoras do racismo, bem como não continham dados específicos sobre o assunto, como por exemplo, fontes que não nos permitiram demonstrar os índices sobre as longas filas para conseguir consultas, nem a demora nos tratamentos, nem o aumento dos riscos clínicos pelas omissões profissionais/institucionais, nem a falta de medicamento e tampouco de acesso aos serviços de saúde (demanda reprimida). Baixa produção temática que também existe na área de Serviço Social.

Produzir informações sobre o racismo e seus impactos pode melhorar a gestão na saúde, encarando as falhas e as limitações para cumprir com a meta da promoção da saúde e da prevenção às doenças. Hoje, as fake news sanitárias estão ainda mais explícitas diante dos impactos da pandemia COVID-19. A informação é imprescindível, precisamos trabalhar mais na divulgação nas comunidades e dentro das instituições de saúde sobre dados que nos levem ao aperfeiçoamento pessoal e profissional, pois o preconceito decorre do senso comum, do desconhecimento e da interdição da fala e da existência do outro. As diretrizes da PNSIPN têm de ser encarnadas pelas equipes de saúde em todos os níveis de atenção do SUS para ser conhecida e referenciada, para tanto, precisamos elaborar também bons materiais didático-informativos com mais representatividade sobre os cuidados com a saúde de negros/as.

O ano de 2020 foi de intensos levantes do Movimento Negro que reuniram multidões em escala mundial, justamente devido ao escancarado racismo institucional que resultou em ações de monitoramento das redes sociais e de seus financiadores, expondo e coibindo os conteúdos/discursos de ódio veiculados em diferentes 
plataformas. Destaque para a campanha "Stop Hate for Profit" instaurada após a divulgação em tempo real da filmagem que registrou a morte do negro estadunidense George Floyd por policial branco, várias vezes denunciado por abusos de autoridade e racismo, que alimentou o Movimento ativista internacional intitulado "Black Lives Metter". No Brasil, temos exemplos cotidianos ilustrando nossas páginas e sites jornalísticos que pouco nos comovem. Eis que 2020 foi ainda mais incisivo na revelação do nosso racismo diário com a morte de Miguel Otávio Santana da Silva aos 05 anos de idade em decorrência da queda do $9^{\text {a }}$ andar de um condomínio de luxo em Recife/PE por negligência da patroa branca de sua mãe (CASO MIGUEL, 2020). Fatos que exemplificam o quão distantes vivemos da igualdade racial, da reparação histórica e dos direitos humanos.

Vida saudável envolve o acesso pleno a outros direitos, bens e serviços (moradia, saneamento, condições de trabalho, educação etc.), conforme problematizam González e Santos (2020) sobre os 10 anos do Estatuto de Igualdade Racial: as lutas que os/as negros/as travam têm motivos concretos e incorporar suas reivindicações na estruturação de políticas públicas as tornam sistemáticas e com capacidade de transformar substantiva e permanentemente suas condições de vida.

A violência racial é demanda para os/as assistentes sociais no acolhimento e no suporte ao/à usuário/a que teve seus direitos violados. Dentre as ações nos serviços de saúde, destacamos: a) a produção de material didático-informativo para ilustrar e potencializar o processo educativo em torno de temas relevantes à promoção da saúde e para a conscientização e divulgação de ações de enfrentamento do racismo institucional; b) o conhecimento do território onde trabalha e do perfil da população a quem atende, dos recursos institucionais e das redes intersetoriais que podem responder às demandas dos/as usuários/as em situação de vulnerabilidade; c) a promoção de cursos de capacitação, compreendendo que o racismo nos transversaliza, impregnando nosso subconsciente e se revelando em atitudes diárias de discriminação; d) mobilização político-organizativa para fortalecer os movimentos negros; e) gestão social, planejamento participativo e transparência nas informações são essenciais para transformar as instituições e as equipes; f) proteção, acolhimento e cuidados interdisciplinares e intersetoriais para fomentar respostas integrais às necessidades dos/as usuários/as. No caso das ações voltadas ao acolhimento e ao atendimento de mulheres negras em Maternidades, as ações voltadas para a saúde mental e para a proteção física dependem da articulação e integralidade das diferentes equipes, políticas e níveis de serviços de saúde. Trata-se da materialização de redes de referência e contrarreferência capazes de dar acompanhamento sistemático e de longo prazo, ultrapassando os cuidados gestacionais; g) amparo e orientação na formalização de queixas crimes, com assessoramento sociojurídico etc.

A pesquisa nos permitiu ainda refletir sobre a saúde das negras impactadas triplamente pela discriminação (classe, raça e gênero). Ao serem retratadas como mulheres fortes e que suportam maus tratos deixam de ser acolhidas, ouvidas e examinadas adequadamente, agravando seu quadro clínico. A observação de campo nos permitiu alcançar indicadores de processo decorrentes do investimento feito no diálogo crítico e científico e na troca de experiências de vida. O vínculo profissionais-usuários/as é fundamental para desmistificar argumentos falaciosos, pois a credibilidade decorre da confiança em saber que existem técnicos/as de referência disponíveis a transmitir informações seguras e consistentes sobre os aspectos cotidianos que preocupam os/as usuários/ as, bem como a amparar suas angústias.

A conjuntura da pandemia COVID-19 precipitou elementos estruturais do racismo, compelindo a população novamente às marchas antirracistas e a reinscrever na cena pública as lutas dos/as negros/as por reconhecimento civil. O aumento da indignação e da repercussão midiática precisa manter o fervor desse engajamento porque posturas antirracistas têm de prevalecer como ganho civilizatório da humanidade ao impactar os modos de vida: profissionais e pessoais. Sabemos que a igualdade racial está distante da realidade, mas precisamos resistir e combater o racismo através da educação racial que encara os erros históricos para fundar uma cultura e uma sociedade radicalmente igualitárias.

\section{Referências}

ASSIS, J. F. de. Interseccionalidade, racismo institucional e direitos humanos: compreensões à violência obstétrica. Revista Serviço Social e Sociedade, São Paulo, n. 133, p. 547-565, dez. 2018. Disponível em: https://www.scielo.br/pdf/sssoc/n133/0101-6628sssoc-133-0547.pdf. Acesso: 12 jun. 2019. 
BRASIL. [Ministério da Saúde]. Secretaria de Gestão Estratégica e Participativa. Departamento de Apoio à Gestão Participativa e ao Controle Social. Política Nacional de Saúde Integral da População Negra: uma política para o SUS. 3. ed. Brasília: Editora do Ministério da Saúde, 2017.

BRASIL. [Presidência da República]. Casa Civil. Lei no 10.639, de 9 de janeiro de 2003. Altera a Lei no 9.394, de 20 de dezembro de 1996, que estabelece as diretrizes e bases da educação nacional, para incluir no currículo oficial da Rede de Ensino a obrigatoriedade da temática "História e Cultura Afro-Brasileira", e dá outras providências. Brasília, DF: Presidência da República, 2003. Disponível em: http://www.planalto.gov.br/ccivil_03/leis/2003/110.639.htm. Acesso em: 21 dez. 2020.

BRASIL. [Senado Federal]. Comissão de Constituição e Justiça. Proposta de Emenda à Constituição n55. Gera a Emenda Constitucional $\mathrm{n}^{\circ}$ 95, de 22 de dezembro de 2016, que altera o Ato das Disposições Constitucionais Transitórias, para instituir o Novo Regime Fiscal, e dá outras providências. Brasília, DF: Diário do Congresso Nacional, 2016. Disponível em https://legis.senado.leg.br/diarios/ ver/20803?sequencia=903 Acesso em 02 fev. 2021.

CASO Miguel: como foi a morte do menino que caiu do $9^{\circ}$ andar de prédio no Recife. G1, São Paulo, 5 jun. 2020. Disponível em: https://g1.globo.com/pe/pernambuco/noticia/2020/06/05/caso-miguel-como-foi-a-morte-do-menino-que-caiu-do-9o-andar-de-prediono-recife.ghtml. Acesso em: 21 dez. 2020.

CERQUEIRA, D. R. C.; MOURA, R. L. de. Vidas Perdidas e Racismo no Brasil. Brasília: Instituto de Pesquisas Econômicas Aplicadas, 2013. (Nota técnica $\left.\mathrm{n}^{\circ} 10\right)$.

CONSELHO FEDERAL DE SERVIÇO SOCIAL. CFESS Manifesta: Dia Nacional da Consciência Negra. Brasília (DF), 20 nov. 2017. Disponível em: http://www.cfess.org.br/arquivos/2017-CfessManifesta-ConscienciaNegra.pdf. Acesso: 20 set. 2019.

CONSELHO FEDERAL DE SERVIÇO SOCIAL. Parâmetros para atuação de Assistentes Sociais na Política de Saúde. Brasília/ DF, 2011. Disponível em: http://www.cfess.org.br/arquivos/Parametros_para_a_Atuacao_de_Assistentes_Sociais_na_Saude.pdf. Acesso: 17 abr. 2019.

CRUZ, I. C. F. da. O Negro Brasileiro e a Saúde: Ontem, Hoje e Amanhã. Revista da Escola de Enfermagem, São Paulo, v. 27, n. 3 , p. 317-27, dez/1993.

CRUZ, I. C. F. da; MONTEIRO, M. do C. S. Racismo Institucional. In: CRUZ, I. C. F. da; MONTEIRO, M. do C. S. Unidade 1: Contextualizando a Saúde da População Negra. Ed. Universidade Aberta do SUS (UMA-SUS), 2016. Disponível em: https://ares. unasus.gov.br/acervo/handle/ARES/2981. Acesso: 28 set. 2019.

CRUZ, I. C. F. da; MONTEIRO, M. do C. S. Módulo 1: Saúde Integral da População Negra. Unidade 1: Contextualizando a Saúde da População Negra. Ed. Universidade Aberta do SUS (UNASUS), 2016a. Disponível em: https://ares.unasus.gov.br/acervo/handle/ ARES/2981. Acesso 28 set. 2019.

CRUZ, I. C. F. da; MONTEIRO, M. do C. S. Módulo1: Saúde Integral da População Negra. Unidade 3: Enfrentamento do Racismo Institucional. Ed. Universidade Aberta do SUS (UNASUS), 2016b. Disponível em: https://ares.unasus.gov.br/acervo/handle/ARES/2978. Acesso 28 set. 2019.

EURICO, M. C. A percepção do assistente social acerca do racismo institucional. Revista Serviço Social e Sociedade, São Paulo, n. 114, p. 290-310, abr./jun. 2013. Disponível em: https://www.scielo.br/scielo.php?pid=S0101-66282013000200005\&script=sci_abstract\&tlng =pt. Acesso em: 12 jun. 2019.

FIGUEIREDO, P. Índice de suicídio entre jovens e adolescentes negros cresce. G1, São Paulo, 21 maio 2019. Disponível em: https:// g1.globo.com/ciencia-e-saude/noticia/2019/05/21/indice-de-suicidio-entre-jovens-e-adolescentes-negros-cresce-e-e-45percent-maiordo-que-entre-brancos.ghtml. Acesso: 07 jul. 2019.

FIGUEIRO, A. V. M.; RIBEIRO, R. L. R. Vivência do preconceito racial e de classe na doença falciforme. Revista Saúde e Sociedade, São Paulo, v. 26, n. 1. mar. 2017, p. 88-99. Disponível em: http://www.scielo.br/scielo.php?script=sci_arttext\&pid=S010412902017000100088\&lng=pt \&nrm=iso. Acesso: 12 jul. 2019.

GONZÁLEZ, A. L. S.; SANTOS, C. A. C. 10 anos do Estatuto da Igualdade Racial: o atraso da reparação persiste. Jornal GGN, [São Paulo], 21 jul. 2020. Disponível em:https://jornalggn.com.br/cidadania/10-anos-do-estatuto-da-igualdade-racial-o-atraso-da-reparacaopersiste-por-ana-lucia-stumpf-gonzalez-e-cecilia-amalia-cunha-santos/. Acesso em: $21 \mathrm{dez} .2020$.

INSTITUTO DE PESQUISA ECONÔMICA APLICADA (IPEA); FÓRUM BRASILEIRO DE SEGURANÇA PÚBLICA (FBSP). Atlas da Violência 2019. Brasília; Rio de Janeiro; São Paulo: IPEA; FBSP, 2019. Disponível em: http://www.forumseguranca.org.br/ wp-content/uploads/2019/06/Atlas-da-Violencia-2019_05jun_vers\%C3\%A3o-coletiva.pdf. Acesso em: 21 dez. 2020.

KALCKMANN, S. et al. Racismo institucional: um desafio para a eqüidade no SUS? Revista Saúde e Sociedade, São Paulo, v. 16, n. 2, p. 146-155, ago. 2007.

LOPES, F. Para além da barreira dos números: desigualdades raciais e saúde. Rio de Janeiro: FIOCRUZ, 2005. Disponível em: https:// www.scielosp.org/scielo.php?pid=S0102311X2005000500034\&script=sci_arttext\&tlng=pt. Acesso: 06 jan. 2019.

PEREIRA, E. G.; RISCADO, J. L. Racismo e saúde mental da criança negra. In: PEREIRA, E. G.; RISCADO, J. L. Raça, Racismo Institucional e práticas na saúde: ensaios reflexões e ações, para implementação da PNSIPN. Maceió: EDUFAL, 2017. p. 167. 
SILVA, F. C. da; PALUDO, K. I. Racismo implícito: um olhar para a Educação Infantil. In: ENCONTRO NACIONAL DE EDUCAÇÃO, 10., 2011, Curitiba. Anais [...]. Curitiba: PUCPR, 2011.

SILVA, H. C. B. População Negra e Racismo Institucional: desafios à concretização do direito à saúde e demandas para o Serviço Social. 2019. Trabalho de Conclusão de Curso em Serviço Social, Universidade Federal de Alagoas, Faculdade de Serviço Social, Maceió, 2019.

\section{Nota}

\section{Helena Clécia Barbosa da Silva}

Helena19256@gmail.com

Assistente Social graduada pela Faculdade de Serviço Social da Universidade Federal de Alagoas (UFAL)

\section{Telma Cristiane Sasso de Lima}

telma.lima@fsso.ufal.br

Doutora pelo Programa de Pós-Graduação da Universidade Federal de Santa Catarina (UFSC)

Professora Coordenadora de Extensão da Faculdade de Serviço Social da Universidade Federal de Alagoas (UFAL)

\section{FSSO/UFAL-Maceió}

Endereço Av. Lourival Melo Mota, S/N

Campus A. C. Simões

Bairro Tabuleiro do Martins

Maceió - AL - Brasil

CEP 57072-900

\section{Agradecimentos}

A Rosilda Vasconcellos da Silva supervisora de campo durante o estágio obrigatório em Serviço Social, por nos apresentar ao tema e pelo seu compromisso ético no enfrentamento cotidiano do racismo no setor da maternidade hospitalar.

\section{Agência financiadora}

Não se aplica.

\section{Contribuições das autoras}

Autora propôs o problema de pesquisa e encaminhou coleta e sistematização dos dados originalmente apresentados no Trabalho de Conclusão de Curso defendido em 30 de outubro de 2019 junto a Faculdade de Serviço Social UFAL/Maceió. A partir dessa pesquisa, a autora estruturou a argumentação principal do artigo, atualizando-o ao escopo da edição temática da Revista. Coautora foi orientadora do Trabalho de Conclusão de Curso da autora, acompanhando-a por dois semestres letivos quando da duração do processo de pesquisa empreendido. Revisou o artigo submetido e ampliou referências aos casos recentes de racismo institucional, cujos dados a autora explorou nos apontamentos conclusivos.

Aprovação por Comitê de Ética

Não se aplica.

Consentimento para publicação

Consentimento das autoras.

Conflito de interesses

Não há conflito de interesses. 